\title{
Free and Open Source Software for Geospatial Applications (FOSS4G) to support Future Earth
}

\author{
Maria Antonia Brovelli*
}

Department of Civil and Environmental Engineering, Politecnico di Milano, Como Campus, Via Valleggio 11, 22100 Como, Italy-maria.brovelli@polimi.it, +39031 3327517

Marco Minghini

Department of Civil and Environmental Engineering, Politecnico di Milano, Como Campus, Via Valleggio 11, 22100 Como, Italy-marco.minghini@polimi.it, +39031 3327540

Rafael Moreno Sanchez

Department of Geography and Environmental Sciences, University of Colorado Denver, 1200 Larimer St Denver, CO 80217 USA - Rafael.Moreno@ucdenver.edu, 303-3523762

Ricardo Oliveira

Department of Geography and Environmental Sciences, University of Colorado Denver, 1200 Larimer St Denver, CO 80217 USA - ricardo.oliveira@ucdenver.edu, 303-2462039

* corresponding author 
The development, integration, and distribution of the information and spatial data infrastructure (i.e. Digital Earth; DE) necessary to support the vision and goals of Future Earth (FE) will occur in a distributed fashion, in very diverse technological, institutional, socio-cultural, and economic contexts around the world. This complex context and ambitious goals require bringing to bear not only the best minds, but also the best science and technologies available. Free and Open Source Software for Geospatial Applications (FOSS4G) offers mature, capable and reliable software to contribute to the creation of this infrastructure. In this paper we point to a selected set of some of the most mature and reliable FOSS4G solutions that can be used to develop the functionality required as part of DE and FE. We provide examples of large-scale, sophisticated, mission-critical applications of each software to illustrate their power and capabilities in systems where they perform roles or functionality similar to the ones they could perform as part of DE and FE. We provide information and resources to assist the readers in carrying out their own assessments to select the best FOSS4G solutions for their particular contexts and system development needs.

Keywords: open source software; geospatial software; FOSS4G; Future Earth; Digital Earth

\section{Introduction}

Future Earth (FE) is a 10-year international research initiative that emerged in 2011 to create a global environmental change research platform to provide more useful and accessible knowledge for decision-makers, and to support the acceleration of the transformation to a sustainable world (Future Earth Norway Secretariat 2015; Future Earth Secretariat 2013). FE focuses on three main research themes: Dynamic Planet; Global Sustainable Development; and Transformations Towards Sustainability (Future Earth Secretariat 2014). It is designed to provide a fundamental, holistic understanding of the interconnections between natural and human drivers of change, the resulting environmental changes, and their implications for human well-being (Future Earth 
Secretariat 2013). These interactions take place across multiple spatial and temporal scales. Being a global effort, the development, integration, and distribution of the information envisioned to be part of FE will occur in very diverse technological, institutional, socio-cultural, and economic contexts around the world. This complex context and ambitious goals require to bring to bear not only the best minds, but also the best science and technologies available.

While FE is conceived as a global research platform for co-creating and codeveloping knowledge, Digital Earth (DE) is the technological framework and infrastructure to realize the FE vision and goals. DE was conceived by Al Gore in 1998 as a multi-scale, multi-resolution, three-dimensional representation of the planet allowing students, scientists, policy-makers and all societal sectors to spatio-temporally navigate and manage georeferenced information (Gore 1998). Recently several authors have argued that, although a number of elements envisioned by Gore have become a reality, some gaps still exist and they propose a new conceptualization of DE more in line with the fast societal and technological changes (Annoni et al. 2011; Goodchild et al. 2012; Craglia et al. 2012; Brovelli et al. 2015a).

Among the multiple areas where collaboration will be needed to implement FE as a DE-based platform for strategic and integrated Earth system research, geospatial information science and technologies will be essential (Craglia et al 2012). More specifically, in this paper we argue that Free and Open Source Software (FOSS) for Geospatial Applications (FOSS4G) can play an important role in data collection, creation of components, integration of information systems, stakeholders' engagement, and dissemination of information that will be essential for the realization of the FE vision. The purpose of this paper is to present an overview of the diversity and sophistication of the FOSS4G software options, provide the readers with resources and 
point to guidelines that can assist them in choosing FOSS4G solutions that match their specific needs and implementation contexts, and finally, illustrate how FOSS4G can contribute to achieve the FE seven key outputs.

FOSS4G are software that provides the user the freedom to run the program for any purpose, access the source code to study how it works and change it, redistribute copies, and redistribute copies of modified versions of the software (GNU Project 1996). The software must comply with the 10 criteria listed in the Open Source Initiative $^{1}$. There is at least one mature sophisticated FOSS4G for every geo-technology area and geospatial information need and application, from data collection in the field, crowdsourcing, desktop applications, spatial extensions to Database Management Systems, to software stacks to create sophisticated Web-based systems using clientserver architectures (Moreno-Sanchez 2012; Steiniger and Hunter 2012). Emerging technologies such as Unmanned Aerial Vehicles (UAV) ${ }^{2}$ and Structure from Motion ${ }^{3}$ are exceptions where the FOSS4G options do not have yet the maturity or robustness for routine deployment; however, several efforts exist such as OpenDroneMap ${ }^{4}$ and $\mathrm{MicMac}^{5}$, respectively. Currently there are over 350 FOSS4G projects listed in FreeGIS.org ${ }^{6}$ and Open Source GIS ${ }^{7}$. Some of these projects have a history that dates back to the early 1980s (e.g. GRASS GIS ${ }^{8}$; Mitasova and Neteler 2004) while others are

1

http://opensource.org/docs/osd

2 https://en.wikipedia.org/wiki/Unmanned_aerial_vehicle

$3 \mathrm{https} / / /$ en.wikipedia.org/wiki/Structure_from_motion

4 http://opendronemap.github.io/odm

5 http://www.micmac.ign.fr

6 http://freegis.org

$7 \mathrm{http}: / /$ opensourcegis.org

$8 \mathrm{http}: / /$ grass.osgeo.org 
more recent and yet have a wide and solid user base, such as Web-GIS platforms (Yao and Zou 2008).

The remainder of the paper is organized as follows. Section 2 provides an overview and categorization of FOSS4G solutions that can be used to address the geospatial information needs of FE. Section 3 discusses criteria for software selection and some of the challenges for adopting FOSS4G; the most common inhibitors and facilitators for FOSS4G adoption are listed. Section 4 presents several existing highimpact applications of FOSS4G related to the seven key focal outputs of the $2025 \mathrm{FE}$ vision. Finally, Section 5 present conclusions and recommendations.

\section{Addressing Future Earth geospatial information needs through FOSS4G solutions}

The creativity, dynamism and high-profile success stories of FOSS/FOSS4G are attracting increasing attention from end users, developers, businesses, governments, educators and researchers around the world (e.g. Weber 2004; Walli et al. 2005; CRMReviews 2006; Faber 2007; Hall and Leahy 2008; Swain et al 2015; Nakayama and Mori 2012). Though findings are varied as to the strengths and weaknesses of FOSS/FOSS4G for specific technological, institutional, socio-cultural and economic contexts and purposes (Erlich and Aviv 2007; Ven and Mannaert 2008), today it is clear that FOSS/FOSS4G provide robust and reliable software besides private/proprietary/closed-source software solutions, and there are opportunities for mutual benefit and complementarity between these two software options for the development of large sophisticated applications (Moreno-Sanchez 2012).

FOSS/FOSS4G have been declared crucial for developing countries because they enable them to develop their own technology instead of having to import it, provide a path to close the digital divide, and can be the base for creating their Spatial 
Data Infrastructures (SDI) in a context where resources for system development and maintenance are scarce (Naronha 2002, 2003; Rajani et al. 2003; Schenker 2003; Wambui 2004; Holmes et al. 2005; Camara and Fonseca 2007; Moreno-Sanchez 2012; Molina and Bayarri 2011). Developed countries are also increasingly using FOSS4G solutions for different reasons (e.g. Marson 2005; Kaneshige 2008; Gillespie 2000; Lettice 2004; Coonan 2004). In both development contexts, FOSS4G fosters creativity, provides healthy competition to private/proprietary/closed-source software, may lead to affordable pricing and increased access, addresses some national security concerns, and reduces dependency on foreign technology.

FOSS/FOSS4G and DE/FE have one important thing in common, the creation, maintenance, and development of both are based on a philosophy of openness, sharing, collaboration and distributed development. This point can not be underestimated. The way technology and its use are approached have broad and deep impacts on the organization and people that use it. If the spatial components of DE and FE are based on technologies that align with the philosophy and spirit of the systems and goals they support, they can have important benefits in fostering a culture of openness, sharing and collaboration (Hippel and Krogh 2003; Stewart and Gossain 2006).

Several overviews and classifications of FOSS4G exist (e.g. Sanz-Salinas and Montesinos-Lajara 2009; Steiniger and Bocher 2009; Steiniger and Hunter 2012 and 2013). Here we concentrate on presenting some mature FOSS4G that can be used to work on the DE technological developments proposed by Craglia et al. (2008) as fundamental to realize the FE vision: 1) Organizing geographic information (related to storing and accessing geodata); 2) Geography as a way to organize information (related to Web-based geo-visualization and geo-processing); 3) Geosensing the world (related to geodata acquired from sensors, including citizen sensors); and 4) Innovation in 
supporting technology (related to general computing technology and hence not addressed here). Table 1 lists these needs/functions and examples of some well-known mature FOSS4G that can be used to address them. The list of FOSS4G is not meant to be comprehensive. The software listed is mature, well know, and with record of successful applications as illustrated in Section 4. 
Table 1. Future Earth major functions/needs with the corresponding software category and examples of FOSS4G projects that can be used to address them.

\begin{tabular}{|c|c|c|c|}
\hline $\begin{array}{c}\text { Area related } \\
\text { to } \mathrm{FE} \\
\text { function/need }\end{array}$ & Software function & FOSS4G category & FOSS4G examples \\
\hline \multirow{5}{*}{$\begin{array}{l}\text { Organizing } \\
\text { Geographic } \\
\text { Information }\end{array}$} & $\begin{array}{l}\text { Desktop visualization } \\
\text { and basic analysis }\end{array}$ & Desktop GIS & $\begin{array}{l}\text { QGIS, gvSIG, uDig, } \\
\text { OpenJUMP, SAGA }\end{array}$ \\
\hline & Geodata storage & $\begin{array}{l}\text { Spatial Database } \\
\text { Management Systems } \\
(\mathrm{DBMS})\end{array}$ & $\begin{array}{l}\text { PostgreSQL/PostGIS, } \\
\text { SQLite/SpatiaLite, } \\
\text { MySQL Spatial, } \\
\text { MongoDB, CouchDB, } \\
\text { Rasdaman }\end{array}$ \\
\hline & $\begin{array}{l}\text { Geodata analysis and } \\
\text { processing }\end{array}$ & $\begin{array}{l}\text { Desktop } \\
\text { geoprocessing and } \\
\text { analysis tools }\end{array}$ & $\begin{array}{l}\text { GRASS GIS, R, } \\
\text { CyberGIS Toolkit }\end{array}$ \\
\hline & $\begin{array}{l}\text { Serving geodata over } \\
\text { the Web }\end{array}$ & $\begin{array}{l}\text { Web-based GIS (e.g. } \\
\text { OGC Web Services } \\
\text { OWS) }\end{array}$ & $\begin{array}{l}\text { GeoServer, MapServer, } \\
\text { QGIS Server, deegree }\end{array}$ \\
\hline & Cataloguing geodata & $\begin{array}{l}\text { Web-based catalogue } \\
\text { services (e.g. OGC } \\
\text { Catalog Services for } \\
\text { the Web CSW) }\end{array}$ & GeoNetwork, pyCSW \\
\hline \multirow{3}{*}{$\begin{array}{l}\text { Geography as a } \\
\text { way to } \\
\text { organize } \\
\text { information }\end{array}$} & 2D Web visualization & 2D Web clients & OpenLayers, Leaflet \\
\hline & 3D Web visualization & Virtual Globes & $\begin{array}{l}\text { NASA World Wind, } \\
\text { Cesium, WebGL Earth, } \\
\text { OpenWebGlobe }\end{array}$ \\
\hline & $\begin{array}{l}\text { Web-based } \\
\text { geoprocessing }\end{array}$ & $\begin{array}{l}\text { Web-based } \\
\text { geoprocessing (e.g. } \\
\text { OGC Web Processing } \\
\text { Services WPS) }\end{array}$ & $\begin{array}{l}\text { pyWPS, ZOO, } 52^{\circ} \text { North } \\
\text { WPS, GeoServer, deegree }\end{array}$ \\
\hline
\end{tabular}




\begin{tabular}{|l|l|l|l|}
\hline Geosensing the & $\begin{array}{l}\text { Geo-referenced data } \\
\text { collection from } \\
\text { specialized sensors }\end{array}$ & $\begin{array}{l}\text { Integration, processing } \\
\text { and distribution of } \\
\text { sensor data (e.g OGC } \\
\text { Sensor Observation } \\
\text { Services SOS) }\end{array}$ & istSOS, 52 ${ }^{\circ}$ North SOS \\
\cline { 2 - 4 } & $\begin{array}{l}\text { Geo-referenced data } \\
\text { collection from mobile } \\
\text { devices and sensors } \\
\text { including citizen } \\
\text { sensors) }\end{array}$ & $\begin{array}{l}\text { Mobile and } \\
\text { geocrowdsourcing } \\
\text { tools }\end{array}$ & $\begin{array}{l}\text { Geopaparazzi, Open Data } \\
\text { Kit (ODK) }\end{array}$ \\
\hline
\end{tabular}

The first area in Table 1 column 1 includes FOSS4G applications able to prepare, store, process, catalog and Web publish geodata. Visualization and basic analysis can be performed using desktop GIS software such as QGIS ${ }^{9}$, gvSIG $^{10}$, uDig ${ }^{11}$, OpenJUMP ${ }^{12}$ and $\mathrm{SAGA}^{13}$. Complex data processing, raster modeling, and statistical analyses can be done using more advanced tools like GRASS GIS ${ }^{14}, \mathrm{R}^{15}$ and the CyberGIS Toolkit ${ }^{16}$. Spatial extensions to Database Management Systems (DBMS) enable them to store geodata and apply a growing number of spatial analytical functions to vector and raster data sets. PostGIS ${ }^{17}$ extends PostgreSQL ${ }^{18}$, SpatiaLite $^{19}$ extends SQLite $^{20}$ DMBS and MySQL implements spatial extensions ${ }^{21}$.

$9 \mathrm{http} / /$ qgis.org

$10 \mathrm{http} / / /$ www.gvsig.com

$11 \mathrm{http}: / /$ udig.refractions.net

$12 \mathrm{http}: / /$ www.openjump.org

$13 \mathrm{http}: / /$ www.saga-gis.org

$14 \mathrm{https} / / /$ grass.osgeo.org

15 https://www.r-project.org

$16 \mathrm{http} / / /$ cybergis.cigi.uiuc.edu/cyberGISwiki/doku.php/ct

$17 \mathrm{http}: / /$ postgis.net

$18 \mathrm{http}: / / \mathrm{www}$. postgresql.org

19 https://www.gaia-gis.it/fossil/libspatialite/index

$20 \mathrm{http}: / / \mathrm{www}$. sqlite.org

$21 \mathrm{http}: / /$ dev.mysql.com/doc/refman/5.7/en/spatial-extensions.html 
No-SQL DBMS like MongoDB ${ }^{22}$ and CouchDB $^{23}$ and multi-dimensional array databases like Rasdaman ${ }^{24}$ also offer capabilities for the storage and management of geodata. Finally, powerful SDI can be created through OGC-compliant FOSS4G tools for serving geodata over the Web (GeoServer ${ }^{25}$, MapServer ${ }^{26}$, deegree ${ }^{27}$ and QGIS Server $^{28}$ ) and cataloguing geodata (GeoNetwork ${ }^{29}$ and pyCSW $^{30}$ ).

Visualization of geodata on the Web is a relatively new field, but it has grown rapidly in recent years (Minghini 2014). Mature FOSS4G products in this area include 2D Web clients built using OpenLayers ${ }^{31}$ and Leaflet ${ }^{32}$ JavaScript libraries. In the 3D Web Virtual Globes such as NASA World Wind ${ }^{33}$, Cesium $^{34}$, WebGL Earth ${ }^{35}$ and OpenWebGlobe ${ }^{36}$ offer powerful platforms for development (a recent overview of Virtual Globes is provided by Brovelli et al. 2013a). Web-based geoprocessing capabilities are also growing rapidly, in this area FOSS4G technologies implementing the reference OGC Web Processing Services $\left(\mathrm{WPS}^{37}\right)$ standard include pyWPS ${ }^{38}$, $\mathrm{ZOO}^{39}, 52^{\circ}$ North $\mathrm{WPS}^{40}$ and again GeoServer and deegree.

22 https://www.mongodb.org

$23 \mathrm{http}: / /$ couchdb.apache.org

$24 \mathrm{http}: / /$ www.rasdaman.com

$25 \mathrm{http} / / /$ geoserver.org

$26 \mathrm{http}: / /$ mapserver.org

$27 \mathrm{http}: / /$ www.deegree.org

$28 \mathrm{http} / / /$ docs.qgis.org/2.2/en/docs/user_manual/working_with_ogc/ogc_server_support.html $29 \mathrm{http} / / /$ geonetwork-opensource.org

$30 \mathrm{http}: / /$ pycsw.org

$31 \mathrm{http}: / /$ openlayers.org

$32 \mathrm{http}: / /$ leafletjs.com

$33 \mathrm{http}: / /$ worldwind.arc.nasa.gov/java

$34 \mathrm{https}: / /$ cesiumjs.org

$35 \mathrm{https} / / /$ www.webglearth.com

$36 \mathrm{http}: / /$ www.openwebglobe.org

$37 \mathrm{http} / / /$ www.opengeospatial.org/standards/wps

$38 \mathrm{http}: / /$ pywps.org

$39 \mathrm{http}: / /$ www.zoo-project.org

40 http://52north.org/communities/geoprocessing/wps 
The last area in Table 1 column 1 includes applications for managing geodata collected by sensors, including both instrument sensors and citizens who act as human sensors (Goodchild 2007). The OGC Sensor Web Enablement (SWE, Botts et al. 2008) allows to process all sensor-like information thanks to a number of standards, these include Sensor Observation Service_(SOS $\left.{ }^{41}\right)$, whose main FOSS4G implementations are istSOS ${ }^{42}$ and $52^{\circ}$ North $\operatorname{SOS}^{43}$, and the new OGC candidate standard SensorThings API ${ }^{44}$ (Open Geospatial Consortium 2015) for managing IoT devices, data, and applications over the Web. This is a new field of application and no mature FOSS4G implementation exists yet. Software for collecting and managing geodata from mobile devices will also play an important role in realizing the vision of FE, prominent examples are Geopaparazzi ${ }^{45}$ and the Open Data Kit (ODK) ${ }^{46}$ suite, Brovelli et al. (2016) demonstrate how they can be used in mobile data collection.

The category of geospatial frameworks is gaining importance. Applications of this kind are not included in Table 1 because they typically consist of combinations of other software products such as: DBMS, geodata servers, geocataloges and Web clients. A notable mature FOSS4G product in this category is GeoNode ${ }^{47}$ based on a powerful software stack that includes PostGIS, GeoServer, GeoNetwork and OpenLayers. It is an SDI-oriented collaboration platform to upload, edit and share geospatial data and maps. After login authentication users can rate and comment maps, thus creating a collaborative platform. A second example is PoliCrowd ${ }^{48}$ (Brovelli et al. 2014), based on NASA World Wind and other FOSS4G products (e.g. PostgreSQL, GlassFish and

$41 \mathrm{http} / / / \mathrm{www} . o p e n g e o s p a t i a l . o r g /$ standards/sos

$42 \mathrm{http}: / /$ istsos.org

$43 \mathrm{http} / / / 52$ north.org/communities/sensorweb/sos

$44 \mathrm{http}: / /$ ogc-iot.github.io/ogc-iot-api/index.html

$45 \mathrm{http}: / /$ geopaparazzi.github.io/geopaparazzi

$46 \mathrm{http}: / /$ opendatakit.org

$47 \mathrm{http}: / /$ geonode.org

$48 \mathrm{http} / /$ geomobile.como.polimi.it/policrowd2.0 
ODK). It is a multi-thematic and multi-dimensional social platform focused on citizensensed data.

Big Data (see Yangyon and Yun 2015 for definition) is a theme that will cut across all the areas in Table 1. Although beyond the scope of this paper, it is worth mentioning that there are mature FOSS for the collection, storage, processing, analysis, transferring and aggregating of Big Data ${ }^{49}$. FOSS4G code libraries (e.g. GDAL/OGR ${ }^{50}$, GeoTools ${ }^{51}$ and Proj4 $\mathrm{J}^{52}$ ) have been also excluded from this overview, but readers must be aware that they are commonly used in all the software categories listed in Table 1. Section 4 will describe a number of large and/or sophisticated real-world implementations of all the software mentioned.

\section{Software selection and challenges for adoption of FOSS4G in the context of}

\section{Future Earth}

Column 3 in Table 1 lists only a sample of FOSS4G options for each niche and geospatial information need that will be part of FE. The number of FOSS4G software options is large, diverse, and rapidly changing (e.g. some of the most frequently used are listed by Holmes et al. 2005; Bruce 2007; Sanz-Salinas and Montesinos-Lajara 2009; Steiniger and Bocher 2009; Garbin and Fisher 2010; Tsou and Smith 2011; Steiniger and Hunter 2012, and 2013; OSGeo-Live DVD ${ }^{53}$ ). The development of FE components will be done in very diverse contexts and conditions. The best FOSS4G solution depends not only of the capability of the software to perform needed tasks at a desired level of performance, but also on the specifics of the technological, institutional, socio-cultural and financial contexts, as well as the backgrounds and levels of expertise

$49 \mathrm{http}: / /$ www.datamation.com/data-center/50-top-open-source-tools-for-big-data-1.html $50 \mathrm{http}: / /$ www.gdal.org

$51 \mathrm{http}: / /$ geotools.org

52 https://github.com/Proj4J/proj4j

$53 \mathrm{http} / / /$ live.osgeo.org/en/index.html 
of the personnel that will develop and maintain the system. Hence, it is difficult to list one or two FOSS4G recommendations for each FE informational need or application. We consider that a more useful approach is to provide the readers with information that will assist them to do their own evaluations and come up with the best FOSS4G solution for their specific context and FE development needs.

FOSS/FOSS4G solutions for FE systems development should be rigorously evaluated at par with private/proprietary/closed-source software in terms of their technical features, reliability, ease of use, documentation, technical support, customizability and extensibility, costs of training, total cost of ownership, support and maintenance, and management requirements (e.g. budget, in-house development team expertise, long-term maintainability) (see Wang and Wang 2001; Woods and Guliani 2005; Ven et al. 2008; Fitzgerald 2011; Chen et al. 2010). Besides these criteria, the evaluation of FOSS4G should include the following nine criteria proposed by the Open Source Geospatial Foundation $\left(\mathrm{OSGeo}^{54}\right)$. OSGeo has developed guidelines for software development $^{55}$; evaluation criteria $^{56}$; and graduation as a high quality sustainable software $^{57}: 1$ ) Open source software is already reasonably mature (working quality code); 2) Project already has a substantial user community; 3) Project already has a substantial and diverse developer community; 4) Project members are aware of, and implement support for, relevant standards (e.g. Open Geospatial Consortium, World Wide Web Consortium, International Organization for Standardization); 5) Project has linkages with existing OSGeo projects; 6) Project fills a gap related to software that OSGeo supports; 7) Project is prepared to develop in an open and collaborative fashion; 8) Project has contributions and interest from more than just one company/organization

$54 \mathrm{http}: / /$ www.osgeo.org/content/foundation/about.html $55 \mathrm{http}: / /$ www.osgeo.org/incubator $56 \mathrm{http}: / /$ www.osgeo.org/incubator/process/evaluation.html $57 \mathrm{http}: / /$ www.osgeo.org/incubator/process/project_graduation_checklist.html 
(see e.g. OSGeo software metrics ${ }^{58}$ ); 9) Project is willing to migrate some or all of its infrastructure (code repository, web site, wiki, mailing list, etc.) to OSGeo support infrastructure, and to adopt a website style consistent with the foundation.

Also, Steiniger and Hunter (2013) present an extensive list of criteria that can be used to evaluate FOSS4G prioritizing them based on the software intended final use (business, research, or teaching). These authors also propose the following FOSS4G evaluation process based on several well-known and tested approaches to software evaluation and adoption: a) Develop software use cases for own context (or "user stories" as used in Agile software development); b) Establish a set of evaluation criteria based on the use cases; c) Perform the software evaluation with respect to the established criteria; d) Develop a weighting criteria according to application context (note, weighting is intended to be flexible so as to allow for different contexts); e) Select the software based on results of the evaluation and weighting scheme.

Several socio-cultural, economic, technological, and organizational issues have been identified as inhibitors or facilitators for the adoption of FOSS/FOSS4G (Giera and Brown 2004; Valimaki et al. 2005; Woods and Guliani 2005; Moreno-Sanchez et al. 2007; Morgan and Finnegan 2007; Viorres et al. 2007; Meeker 2008; Ellis and Van Belle 2009; Hauge et al. 2010; Nagy et al. 2010). Without being comprehensive lists and based on these authors, here are some we consider are more likely to emerge as part of FE developments. Inhibitors: a) Lack of awareness of software existence, relevance, or successful implementations, shortage of technical knowledge needed to implement and use it; b) organization has a favourable arrangement with a proprietary vendor (e.g. discounts; training or support); c) big/expensive prior investments in proprietary software infrastructure, changing operating model can be problematic; d) staff

$58 \mathrm{http} / / /$ live.osgeo.org/en/metrics.html 
resistance due to fear of being deskilled if using FOSS4G instead of commercial packages; e) shortage of providers, expertise, and traditional support; f) customization needs; g) lack of clarity on licensing issues; h) hidden costs (e.g. training and configuration; premium professional support; need to dedicate resources to community participation). Facilitators: a) FOSS4G technological/costs benefits outweigh its disadvantages/concerns; b) availability of FOSS4G-literate personnel; c) top management support for FOSS4G; existence of a committed and respected FOSS4G inhouse champion; d) limited financial resources ensure FOSS4G consideration; e) FOSS4G can help bridge countries' cross-border technological and budgetary disparities and facilitate cooperation.

Much progress has been done in recent years to address some the inhibitor issues and enhance the facilitator ones. Major FOSS4G community groups and initiatives are enhancing awareness, facilitating access to support materials and education, establishing best practices, designing systematic approaches to ensure software can be trusted, assessing software integrity and security, and sharing successful implementation experiences (e.g. "GeoForAll” international network of FOSS4G labs ${ }^{59}$; Geoacademy ${ }^{60}$; The Open Source Observatory Europe ${ }^{61}$; EU-Free and Open Source Software Auditing Project $^{62}$ and the EU CASCADOSS project ${ }^{63}$ ).

\section{Example of FOSS4G-based system}

In this section we present how FOSS4G applications are related to the outputs of the FE 2025 vision described by the Future Earth Secretariat (2014). We use the spatial information system architecture depicted in Figure 1 to illustrate the following

$59 \mathrm{http}: / /$ www.geoforall.org

$60 \mathrm{http}: / /$ fossgeo.org

$61 \mathrm{https} / / /$ joinup.ec.europa.eu/community/osor/home

$62 \mathrm{https} / / /$ joinup.ec.europa.eu/node/148101

$63 \mathrm{http}: / /$ www.gisat.cz/images/upload/7abfb_cascadoss-flyer-en.pdf 
presentation. It is based on the three DE technological areas proposed by Craglia et al. (2008) and used in Section 2 to classify FOSS4G technologies: Organizing Geographic Information, Geography as a way to organize information, and Geosensing the World. Instead of one or few pieces of software which perform multiple functions (typical of proprietary solutions), system architectures based on FOSS4G are modular, composed of multiple software and technologies interacting with each other through the use of open standards and open formats. In Figure 1 the seven key focal outputs of the 2025 FE vision are noted in boxes (some of them are shortened for space reasons). The position where they are placed in Figure 1 relates to the FOSS4G class that is best suited to contribute to its implementation. 


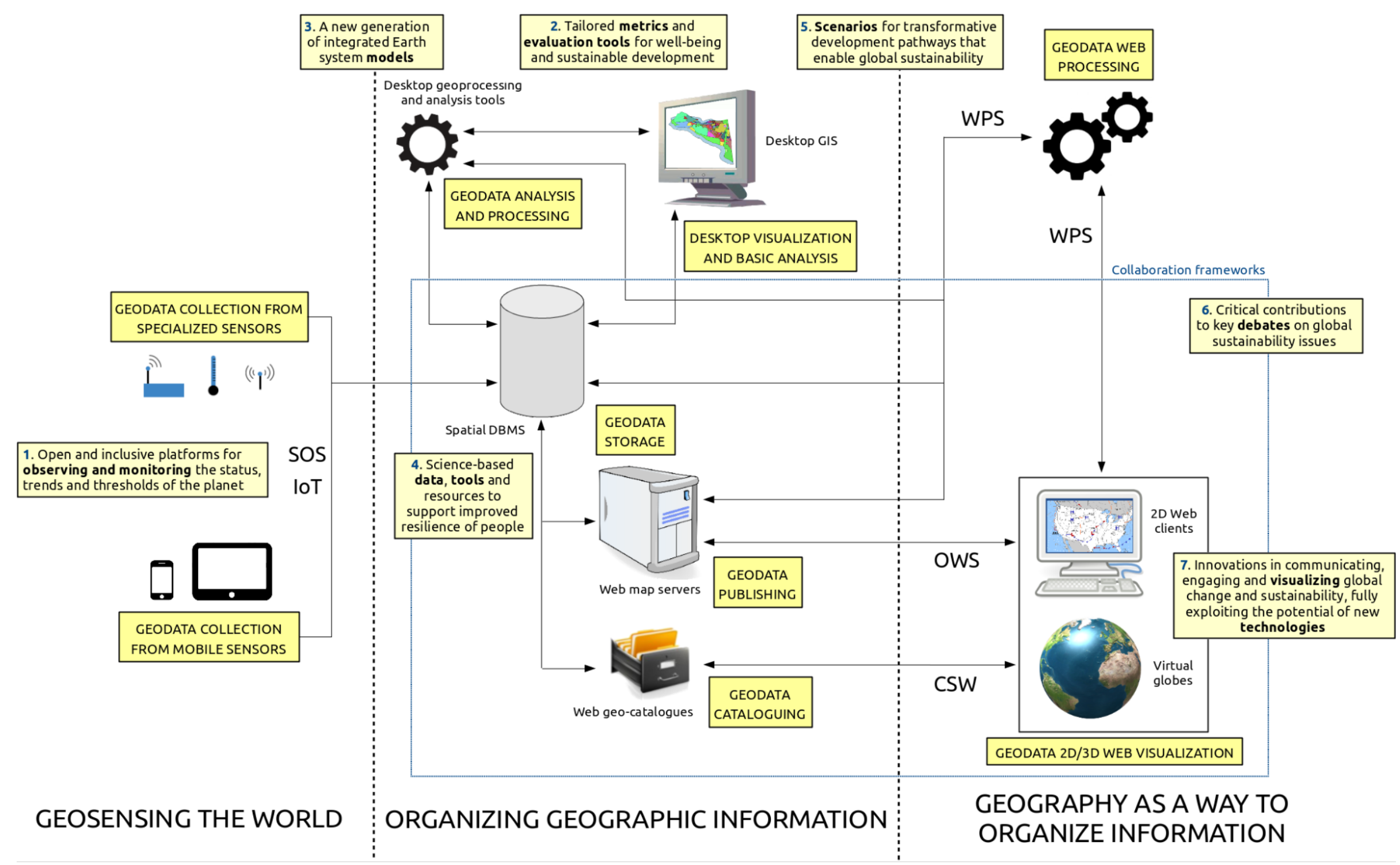

Figure 1. Architecture of a spatial information system to illustrate how FOSS4G can contribute to the achievement of the seven FE key focal outputs. 
The following subsections present examples of real-world, high-impact FOSS4G applications related to each of the seven FE key outputs noted in Figure 1. The purpose is to illustrate the suitability and capability of FOSS4G to fulfill the needs and requirements of $\mathrm{FE}$.

\subsection{Open and inclusive platforms for observing and monitoring the status, trends and thresholds of the planet in a timely manner at different scales, including tracking fast-changing sentinel processes and systems}

This FE need is addressed by systems that support the collection, storage, management, analysis and reporting of environmental data in real-time or almost real-time. Such systems can be fully based on FOSS/FOSS4G software options. This area primarily includes FOSS4G applications for managing observations collected from monitoring sensors. For instance, istSOS has been used in the EU ENORASIS project ${ }^{64}$ as the basis of a Decision Support System (DSS) to optimize irrigation management by farmers and water management organizations (Cannata and Antonovic 2015a). It is also used in the Integrated Management of Red River System (IMRR) project to manage observational data collected by sensors in the Red River Basin (Vietnam) ${ }^{65}$ for the purpose of visualizing, analyzing, and comparing different planning alternatives for the management of the river water system (Arias et al. 2015). $52^{\circ}$ North SOS implementation is used to report air quality data from different European member states to the European Environment Agency (EEA) with the purpose of improving the flow of near-real time air quality data across Europe (Jirka et al. 2015). $52^{\circ}$ North Sensor Web

64

http://enorasis.eu

65 http://tinyurl.com/jq8427j 
tools are also applied in the field of oceanography to build ocean observatories, such as in the $\mathrm{NeXOS}^{66}$, ODIP $\mathrm{II}^{67}$ and FixO3 ${ }^{68}$ EU projects (Jirka et al. 2014).

There are also several FOSS4G crowdsourcing tools that allow a real-time sensing of our planet. ODK is been used by: the Amazon Conservation Team ${ }^{69}$ to monitor deforestation in the Amazon; the African Soil Information Service ${ }^{70}$ to map soil conditions; the Harvard Humanitarian Institute ${ }^{71}$ to document human rights violations; the Haiti Regeneration Initiative ${ }^{72}$ to monitor agricultural practices, crop productivity, and farmer yields of crops; and D-tree ${ }^{73}$ to identify and treat severely malnourished children in a UNICEF-funded project. Brovelli et al. (2015b) exploit ODK in a number of projects related to urban planning. Projects based on Geopaparazzi include the development of the Disaster Management Information System of Osaka City ${ }^{74}$; Gasdroide ${ }^{75}$, a system for $\mathrm{CO}_{2}$ monitoring through the link between Geopaparazzi and an ad hoc sensor; Trackoid $^{76}$, a mobile application for realtime fleet and rescue teams coordination; and support for forest field surveys for the Japanese forestry governmental agency ${ }^{77}$. Finally, despite being a desktop GIS uDig was installed on the portable computers of FAO personnel carrying out agricultural monitoring activities in remote locations $^{78}$.

$66 \mathrm{http}: / /$ www.nexosproject.eu

$67 \mathrm{http}: / /$ www.odip.eu

$68 \mathrm{http}: / / \mathrm{www}$. fixo3.eu

$69 \mathrm{http}: / /$ www.amazonteam.org

$70 \mathrm{http}: / /$ africasoils.net

$71 \mathrm{http}: / /$ hhi.harvard.edu

$72 \mathrm{http}: / /$ www.haitiregeneration.org

$73 \mathrm{http}: / /$ www.d-tree.org

$74 \mathrm{http} / / /$ tinyurl.com/gwqnocg

75 https://bitbucket.org/moovida/gasdroide/wiki/Home

$76 \mathrm{http}: / /$ www.trackoid.eu

$77 \mathrm{http} / / / \mathrm{www}$. slideshare.net/KouichiKita/qgisgis

$78 \mathrm{http} / /$ www.refractions.net/expertise/casestudies/2005-12-unfao/ 
Web platforms offering real-time monitoring of the Earth can be also included in this area. The monitoring platform of polar regions and cryosphere, maintained by Polar View $^{79}$, is a notable example of the use of GeoServer for seamlessly providing large volumes of data ${ }^{80}$, including EO data. GeoServer and OpenLayers are also used within the EUMETSAT map viewer ${ }^{81}$ offering weather and climate monitoring from space, and within the LaMMA geoportal ${ }^{82}$ which provides global, real-time weather observations.

The area of Big Data is not covered in this paper. However, the collection, storage, manipulation, analysis and distribution of very large volumes of spatial data will be important activities as part of DE and FE. The CyberGIS ${ }^{83}$ project aims to establish a fundamentally new software framework via a seamless integration of cyberinfrastructure, GIS, and spatial analysis/modeling capabilities. Part of this project is the CyberGIS Toolkit ${ }^{84}$, a suite of loosely coupled open-source geospatial software components that provide computationally scalable spatial analysis and modeling capabilities enabled by advanced cyberinfrastructure.

\subsection{Tailored metrics and evaluation tools for well-being and sustainable development}

This FE output requires the combination and analysis of socio-economic and environmental data coming from diverse sources to generate metrics and indicators of well-being and sustainable development. Systems that incorporate database management systems with spatial extensions such as PostgreSQL-PostGIS, desktop GIS systems such as QGIS or GRASS GIS, and custom analytical software can be used as platforms to seamlessly integrate and analyze this diverse information. Then other

$79 \mathrm{http}: / /$ www.polarview.org $80 \mathrm{http}: / /$ www.polarview.aq

$81 \mathrm{http} / / /$ eumetview.eumetsat.int/mapviewer

$82 \mathrm{http}: / /$ geoportale.lamma.rete.toscana.it/MapStore/public

$83 \mathrm{http}: / /$ cybergis.cigi.uiuc.edu/cyberGISwiki/doku.php

84 http://cybergis.cigi.uiuc.edu/cyberGISwiki/doku.php/ct 
FOSS4G can be used to provide access and distribute the information over the Web (e.g. GeoServer, OpenLayers). An important example is the EU Recharge Green project ${ }^{85}$, which has developed a DSS using GRASS GIS and a QGIS plugin (Garegnani et al. 2015 ) to study the impact of exploiting renewable energy sources in the Alps. GRASS GIS was also used within the SOLAREC (Photovoltaic and solar electricity) EU project $^{86}$, aimed at implementing renewable energy in the EU as a sustainable and longterm energy supply. The Photovoltaic Geographical Information System (PVGIS) ${ }^{87}$ provides a map-based inventory of solar energy resources and assessment of the electricity generation from photovoltaic systems (Š́ri et al. 2007). The project WebGIS $^{88}$, fully based on GRASS GIS, implements the solar radiation model (Hofierka and Súri 2002) to compute the photovoltaic potential on Europe. The Pakistan Agriculture Information System ${ }^{89}$, which integrates many FOSS4G packages such as GeoServer, GeoNetwork and OpenLayers, provides a rich set of analyses and geoprocessing of data of Pakistan's crops and agro-meteorological variables. Similarly, the Global Atlas for Renewable Energy of IRENA (International Renewable Energy Agency $)^{90}$, is based on GeoServer and OpenLayers, it offers high quality data for solar and wind project assessments and policy planning. The geoUmbriaSUIT QGIS plugin ${ }^{91}$ performs sustainability assessment in a GIS environment using a multi-criteria algorithm based on environmental, economic and social criteria.

$85 \mathrm{http} / / /$ www.recharge-green.eu $86 \mathrm{http}: / /$ cordis.europa.eu/project/ren/64623_en.html $87 \mathrm{http} / / / \mathrm{re} . j \mathrm{rc}$. ec.europa.eu/pvgis/index.htm $88 \mathrm{http}: / /$ re.jrc.ec.europa.eu/pvgis/apps4/pvest.php\# $89 \mathrm{http} / / /$ cip-pakistan.geo-solutions.it/MapStore $90 \mathrm{http}: / /$ irena.masdar.ac.ae 91 https://plugins.qgis.org/plugins/geoUmbriaSUIT 


\subsection{A new generation of integrated Earth system models to deepen our understanding of complex Earth systems and human dynamics across different disciplines, and to underpin systems-based policies and strategies for sustainable development}

The efficient and timely creation of complex integrated Earth system models capable to analyze and simulate diverse conditions and changes will require the reuse of functionality already available in FOSS/FOSS4G software and the development of new ones. FOSS/FOSS4G is uniquely poised to make major contributions in this arena for two reasons. First, FOSS4G already offers a suit of sophisticated analytical capabilities, and second, because the source code is open and modular, developers can integrate FOSS4G, or extract and reuse some of their functionality to incorporate it into larger more complex analytical and simulation systems of both physical and humanenvironment interactions. For example, GRASS GIS has been extensively used for modeling the ecology of both plant and animal invasive species (e.g. Pitt et al. 2011; Neteler et al. 2011; and the GlobalChangeBiology project ${ }^{92}$ ). It has been also used to simulate and predict the long-term evolution of the Paneveggio forest (northern Italy) based on changes in human activities (Tattoni et al. 2011) and to correlate changes in the agro-forest landscape with the loss of traditional ecological knowledge (Ianni et al. 2015). GRASS GIS and R have been used to monitor the presence of primates in relation to human disturbances (Cavada et al. 2016). Designed around QGIS, the Water Observation and Information System (WOIS) ${ }^{93}$ is a decision support tool that integrates processing and hydrological modelling for cost-effective management of water resources in Africa. A plugin ${ }^{94}$ for gvSIG based on JGrassTools ${ }^{95}$ performs modelling

$92 \mathrm{https} / / /$ sites.google.com/site/globalchangebiology

$93 \mathrm{http}: / /$ qgis.org/en/site/about/case_studies/africa_tiger.html

94 http://outreach.gvsig.org/case-studies/gis-tools-water-supply-systems-implementation-usingjgrasstools-and-gvsig

95 https://github.com/moovida/jgrasstools 
and simulation to optimize management of water supply systems, while SAGA is used for the spatial modelling of natural hazards in the Bavarian Alps (Kerkhof and Becht 2006). The Global Disaster Alert and Coordination System (GDACS) ${ }^{96}$, jointly developed by the European Commission and the UN, combines Web-based geoprocessing using ZOO WPS and GRASS GIS to alert the international community in case of major sudden disasters. Finally, ZOO WPS was used to create DSS for rainfall modelling as part of a FOSS4G architecture to build a geoportal for North Vietnam (Brovelli et al. 2013b).

\subsection{Science-based data, tools and resources to support improved resilience of people, communities and economies, including disaster risk reduction}

The production of science-based data is increasing at an exponential rate. The processing of big amounts of data in a timely fashion is becoming a major challenge. To approach these types of issues Spatial Databases, such as PostGIS, are becoming an invaluable tool. In the United States at the National Renewable Energy Lab (NREL) ${ }^{97}$ PostGIS is being used to process data in an effective and scalable manner to support the institution's mission (Getman 2015). SpatiaLite is also commonly used worldwide thanks to its simplicity, ease of use and flexibility. Apart from its well-known integration in other FOSS/FOSS4G projects (e.g. Debian, Fedora, GDAL, QGIS, R, Geopaparazzi and OpenStreetMap), SpatiaLite is currently used for FE-related needs by a large number of organizations such as the managers of the Yellowstone National Park and Idaho nature reserves, the Mozambique government, the World Health Organization (WHO) to monitor bird flu in the Southeast Asia, and the National Oceanic and Atmospheric Administration (NOAA) for oceanic studies. These applications were

$96 \mathrm{http}: / /$ www.gdacs.org 97 http://www.nrel.gov 
described by Alessandro Furieri, the creator of SpatiaLite, in a personal communication to the authors on February 19, 2016. An important application of Rasdaman is the storage of netCDF output files generated by the Global Flood Awareness System $(\text { GloFAS })^{98}$, which uses a hydrological model to produce daily river flood forecasts at the global scale. Rasdaman is also at the core of the EU EarthServer project ${ }^{99}$, which is building a platform for optimizing access to big data from Earth observation systems. Applications of MySQL Spatial include the Korean local governments management systems of their water supply network and hazardous material transportation. CouchDB is used in an online planning support system to predict fire behaviour (Choi et al. 2015). MongoDB is used in an application performing spatio-temporal visualization and analyses of telecommunication data flows in urban areas (Brovelli et al. in press).

The role of geodata catalogues is crucial to manage, describe, search and retrieve geospatial data. Applications of GeoNetwork (which integrates other FOSS4G tools like OpenLayers) have been deployed by diverse organizations such as the geocatalogues of the Food and Agriculture Organization (FAO) ${ }^{100}$, the Netherlands Environmental Assessment Agency ${ }^{101}$, the Australian Institute of Marine Science ${ }^{102}$, the ISRIC - World Soil Information ${ }^{103}$, the Netherlands Coordination Office of the UN Spatial Data Infrastructure (UNSDI) ${ }^{104}$, and the geoportal of the Global Earth Observation System of Systems (GEOSS) $)^{105}$. A noteworthy implementation of pyCSW is the Platform for

$98 \mathrm{http}: / / \mathrm{www} . g$ lobalfloods.eu $99 \mathrm{http}: / / w w w . e a r t h s e r v e r . e u$ $100 \mathrm{http}: / /$ www.fao.org/geonetwork $101 \mathrm{http}: / /$ geoservice.pbl.nl/geonetwork/srv/en/main.home $102 \mathrm{http} / /$ data.aims.gov.au/geonetwork/srv/eng/main.home $103 \mathrm{http} / / / 85.214 .194 .220 /$ geonetwork/srv/en/main.home $104 \mathrm{http}: / /$ www.geonetwork.nl $105 \mathrm{http}: / / \mathrm{www} . g e o p o r t a l . o r g$ 
Urban Management and Analysis (PUMA) ${ }^{106}$ of the World Bank, focused on the study of urban and population expansion.

A significant example of a fully FOSS4G-based project to support the use and reuse of data is Publica Mundi ${ }^{107}$. It uses several FOSS4G here mentioned including Rasdaman, PostGIS, ZOO, GeoServer and OpenLayers to support the full life cycle of open geospatial data and enable the development of cross-boundary, demand-aware and scalable applications. ZOO WPS is also used together with other FOSS4G tools for the Osaka City University Disaster-risk Reduction Project (ODRP) ${ }^{108}$, a WebGIS system based on OpenLayers to promote disaster risk awareness through community disaster prevention education. $\mathrm{ZOO}$ is used for computing on the Web both the risk factor of buildings and the routes to the nearest rescue shelter.

\subsection{Scenarios for transformative development pathways that enable global sustainability, to help evaluate different strategies and options}

This FE need requires the support of systems that can clearly and eloquently present information on current conditions, and illustrate scenarios in a compelling way that inspire people and institutions to change toward sustainable development alternatives. Both desktop and Web-based FOSS4G technologies can be used to run model simulations and evaluate/choose optimal alternatives for meeting sustainable development goals. GRASS GIS was used as early as the 1990's as a modeling and simulation platform in a DSS for hazardous waste management (Frysinger et al. 1993). A more recent example is the SITGAP DSS (Cannata and Antonovic 2015b) used by the Civil Protection Agency of Locarno and Vallemaggia (Switzerland). The system is based on an open source architecture that uses PostGIS, GeoServer, istSOS, pyWPS and

$106 \mathrm{http}: / /$ puma.worldbank.org $107 \mathrm{http}: / /$ www.publicamundi.eu 108 http://wps.media.osaka-cu.ac.jp/osaka 
OpenLayers. The system integrates several information sources to perform hydrological modeling, provide meteorological forecasts and evaluate risk scenarios. Similarly, the above mentioned ENORASIS and IMRR projects perform natural resources management optimization using FOSS/FOSS4G software. The former implements the well-known Weather Research \& Forecasting (WRF) open source model ${ }^{109}$, while the latter is based on an open source stack including Drupal, istSOS, Geoserver, OpenLayers and Octave.

\subsection{Critical contributions to key debates on global sustainability issues, including inputs to scientific assessments and decision-relevant syntheses}

Robust and well-established FOSS4G (as well as private/proprietary/closed-source) applications in this field have yet to be developed. However, an interesting start in this direction is provided by the collaboration frameworks mentioned in Section 1. Among the notable implementations of GeoNode the following are worth mentioning. The Joint Research Center (JRC) of the European Commission, created an SDI to collect and disseminate results of geospatial analysis related to the assessment of the impact of the Syrian crisis ${ }^{110}$. The UN World Food Program (WFP), created a platform to enhance preparedness for humanitarian emergencies ${ }^{111}$. The US Department of State, created an application for publishing open geodata produced by government agencies to support decision-makers and partners during complex emergencies, natural disasters, and diplomatic activities worldwide ${ }^{112}$. GeoNode is also used in a collaboration platform created by the World Bank to share geospatial data for the development of Haiti ${ }^{113}$, and as an integrated management platform for enhancing environmental monitoring and

$109 \mathrm{http}: / /$ www.wrf-model.org

$110 \mathrm{http}: / /$ geonode.jrc.ec.europa.eu

$111 \mathrm{http}: / /$ geonode.wfp.org

$112 \mathrm{http} / /$ geonode.state.gov

$113 \mathrm{http}: / /$ haitidata.org 
inform decision-making in the Caribbean region ${ }^{114}$. An important open source application built on top of GeoNode is GeoSHAPE (Geospatial capabilities for Security, Humanitarian Assistance, Partner Engagement) ${ }^{115}$, designed to enable geo-collaboration between mission partners in coordinated and uncoordinated operations. The most relevant application of PoliCrowd is on a platform for sustainable tourism in northern Italy (Brovelli and Zamboni 2015).

\subsection{Innovations in communicating, engaging and visualising global change and sustainability, fully exploiting the potential of new technologies and overcoming differential access to information across the world}

FOSS/FOSS4G in this area can play an important role by facilitating access to cuttingedge software and functionality and helping to reduce the digital divide that separates developed from developing nations (James 2003). Also, the visualization capabilities available in several FOSS4G such as in 2D and 3D Web clients (which often represent the only visible part of the architecture depicted in Figure 1) enable the interactive visualization of geospatial data stored in databases published through the Web. Examples of 2D applications based on FOSS4G are the OSM (OpenStreetMap) Tasking Manager ${ }^{116}$ used by HOT (Humanitarian OpenStreetMap Team) to coordinate the collaborative mapping in areas hit by natural disasters, and the forecast viewer ${ }^{117}$ of the GloFAS system mentioned above. The former makes use of Leaflet, while the latter uses MapServer and OpenLayers for the display of data. MapServer and OpenLayers were also used to create the popular Minnesota Department of Natural Resources ${ }^{118}$ WebGIS system. Coupled with GeoServer, OpenLayers is also used by FAO to display global

$114 \mathrm{http}: / / \mathrm{c}-\mathrm{read} . \mathrm{net}$

$115 \mathrm{http}: / /$ geoshape.org

$116 \mathrm{http}: / /$ tasks.hotosm.org

$117 \mathrm{http}: / /$ www.globalfloods.eu/glofas-forecasting

$118 \mathrm{http} / / / \mathrm{www} . d n r . s t a t e . m n . u s / m a p s /$ compass.html 
major fishing areas of tunas and billfishes ${ }^{119}$ and aquatic species distribution ${ }^{120}$. PostGIS, GeoServer and OpenLayers are the foundation of the geoportal ${ }^{121}$ for GlobeLand30, the first global land cover dataset at 30 meters resolution (Chen et al. 2014; Han et al. 2015). It is worth mentioning that the first accuracy assessment of this dataset at a national level was also performed using FOSS4G (Brovelli et al. 2015c). The map viewer of ESA Sentinels Scientific Data Hub ${ }^{122}$, which provides distributed mirror archives and bulk dissemination capabilities for the EO Sentinels products, is based on OpenLayers also. It is worth mentioning that the geoportal of the Swiss

Confederation $^{123}$, is also built using OpenLayers. It was recently awarded the "2015 eGovernment special prize" (Swiss Confederation 2015). Many applications of OpenLayers have been also described in the previous subsections. A system featuring OpenLayers and Leaflet viewers as well as several other FOSS4G solutions (PostGIS, MySQL, MapServer, GeoServer, deegree and GeoNetwork) is the Bolivia’s SDI, named GeoBolivia ${ }^{124}$.

Among 3D systems using open source Virtual Globes it is worth mentioning EOLi (Earth Observation Link), the European Space Agency's (ESA) client for Earth Observation Catalogue and Ordering Services ${ }^{125}$, and a monitoring tool ${ }^{126}$ developed by the US Federal Aviation Administration (FAA) providing meaningful visualizations of rich amounts of data at various scales. Both are based on World Wind (a Virtual Globe developed by NASA). World Wind is also embedded in the ESA SNAP (Sentinel

$119 \mathrm{http}: / /$ www.fao.org/figis/geoserver/tunaatlas

$120 \mathrm{http} / / / \mathrm{www}$. fao.org/figis/geoserver/factsheets/species.html

$121 \mathrm{http} / / /$ www.globallandcover.com

$122 \mathrm{https} / / /$ scihub.copernicus.eu/dhus/\#/home

$123 \mathrm{http}: / /$ www.geo.admin.ch

124 http://geo.gob.bo

$125 \mathrm{https}: / /$ earth.esa.int/web/guest/eoli

$126 \mathrm{http}: / /$ worldwind.arc.nasa.gov/temp/faa/NESAT3DDemo.mp4 
Application Platform) Desktop application ${ }^{127}$, which allows to visualize and process Sentinel and other EO data, and in the Wildfire Management Tool (WMT) ${ }^{128}$ which implements an advanced model to predict fire behaviour. Among Cesium's applications related to FE themes it is worth mentioning the $3 \mathrm{D}$ Harvesting Planter ${ }^{129}$, a decision making environment for forestry management, and the mobile Web app WAVE (Waterway information for Vessels) $)^{130}$, providing emergency information to fishermen in Louisiana. Finally, the energyglobe application ${ }^{131}$ exploits WebGL Earth virtual globe for visualizing global energy patterns over time.

Also worth mentioning are systems that incorporate physical models with 2D and 3D such as the Tangible Landscape system ${ }^{132}$. This system is a collaborative modelling environment for analysis of terrain changes. It combines a scanner, projector and a physical 3D model with GRASS GIS to analyse the impact of terrain changes by capturing the changes on the physical model, bringing them into the GIS, performing desired analysis or simulation and projecting the results back on the model in real-time (Petrasova et al. 2015).

\section{Conclusions and recommendations}

The reasons for FOSS/FOSS4G adoption vary from pragmatic to ideological, but they should be based not only on their technical merit, their no-cost feature, or their access to the source code. Adopting FOSS/FOSS4G for the wrong reasons can have unintended consequences, while not adopting them might leave considerable opportunities and benefits unused (Moreno-Sanchez 2012). FOSS4G software should be evaluated at par

$127 \mathrm{http}: / /$ step.esa.int/main/download

$128 \mathrm{http}: / /$ www.emxsys.com

129 https://cesiumjs.org/demos/3DHarvestingPlanner.html

$130 \mathrm{https}: / /$ cesiumjs.org/demos/WAVE.html

$131 \mathrm{http}: / /$ energyglobe.paperplane.io

132 https://geospatial.ncsu.edu/osgeorel/tangible-landscape.html 
with their private/proprietary/closed-source counterparts to select the solution that best addresses the context and informational needs where they will be used to develop the components, systems, and functionality that will be part of DE and FE. FOSS4G capabilities, range of applications, and user/developer/education communities have been growing and maturing rapidly around the world. Today there are more implementation experiences, educational resources, personnel know-how, commercial support services, and larger more experienced user/developer communities. These developments, among others, are reducing the impact of inhibitors that in the past have impacted the uptake of FOSS/FOSS4G solutions.

Because of their purpose and ultimate goals, DE and FE will be developed and maintained around the world following a philosophy of openness, sharing, and distributed-collaborative development. Technologies like FOSS/FOSS4G that align with this philosophy by being open, breaking barriers, facilitating access, and fostering the creation of communities of interest will play an important role in realizing the DE and FE visions. This paper has shown that there are already many stable implementations of FOSS4G solutions in high-level organizations working on large, sophisticated, missioncritical operations. These examples demonstrate the robustness, reliability and suitability of FOSS4G for contributing to achieve the FE vision and goals. Thanks to their modularity, openness, and extensibility, FOSS4G solutions are positioned to contribute to the realization of DE and FE visions. FOSS4G and its user/developer/education communities are clearly ready and capable to contribute to the FE endeavor, no doubt one of the most critical of the 21 st century. 


\section{Acknowledgements}

The authors would like to sincerely thank the many people who provided references and links to the meaningful FOSS4G applications listed in Section 4.

\section{References}

Annoni, A., Craglia, M., Ehlers, M., Georgiadou, Y., Giacomelli, A., Konecny, M., Ostlaender, N., Remetey-Fülöpp, G., Rhind, D., P. Smits, and S. Schade. 2011. “A European perspective on Digital Earth." International Journal of Digital Earth 4 (4): 271-284. doi:10.1080/17538947.2011.582888

Arias, C., Brovelli, M. A., Corti, S., Micotti, M., E. Weber, and R. S. Sessa. 2015. “A FOSS approach to Integrated Water Resource Management: the case study of Red-Thai Binh rivers system in Vietnam.” Geomatics Workbooks 12: 471-476. http://geomatica.como.polimi.it/workbooks/n12/FOSS4Geu15 submission 100.pdf (accessed: 28 Feb 2016)

Botts, M. Percivall, G., C., Reed, and J. Davidson. 2008. “OGC® sensor web enablement: Overview and high level architecture." In GeoSensor networks, edited by A. Stefanidis, and S. Nittel, 175-190, CRC Press. doi:10.1007/978-3540-79996-2_10

Brovelli, M. A., Hogan, P., M. Minghini, and G. Zamboni. 2013a. "The power of Virtual Globes for valorising cultural heritage and enabling sustainable tourism: NASA World Wind applications." International Archives of the Photogrammetry, Remote Sensing and Spatial Information Sciences XL-4/W2: 115-120. doi:10.5194/isprsarchives-XL-4-W2-115-2013

Brovelli, M. A., Quang, T. X., and G. Fenoy. 2013b. "Managing Satellite Precipitation Data (PERSIANN) Through Web GeoServices: A Case Study in North Vietnam.” In Intelligent Systems for Crisis Management, edited by Zlatanova, S., Peters, R., Dilo, A., and H. Scholten, 159-170. Springer Berlin Heidelberg. doi:10.1007/978-3-642-33218-0_12

Brovelli M. A., Minghini M., and G. Zamboni. 2014. "Three dimensional Volunteered Geographic Information: a prototype of a social virtual globe”. International 
Journal of 3-D Information Modeling 3 (2): 19-34.

doi:10.4018/ij3dim.2014040102.

Brovelli, M. A., and G. Zamboni. 2015. "A 3D social platform for the Paths of Via Regina." International Archives of Photogrammetry, Remote Sensing and Spatial Information Sciences XL-4/W7: 23-30. doi:10.5194/isprsarchives-XL-4W7-23-2015

Brovelli, M. A., Zamboni, G., and C. A. Muñoz. 2015a. "From paper maps to the Digital Earth and the Internet of Places.” Rendiconti Lincei 26 (1): 97-103. doi:10.1007/s12210-015-0437-y

Brovelli, M. A., Minghini, M. and Zamboni G. 2015b. "Public Participation GIS: a FOSS architecture enabling field-data collection." International Journal of Digital Earth 8 (5): 345-363. doi:10.1080/17538947.2014.887150.

Brovelli, M. A., Molinari, M. E., Hussein, E., Chen, J., and R. Li. 2015c. "The first comprehensive accuracy assessment of GlobeLand30 at a national level: methodology and results." Remote Sensing 7(4), 4191-4212. doi:10.3390/rs70404191

Brovelli, M. A., Minghini, M., and G. Zamboni. 2016. "Participation in GIS via mobile applications". ISPRS Journal of Photogrammetry and Remote Sensing 114, 306315. doi:10.1016/j.isprsjprs.2015.04.002.

Brovelli, M. A., M. Minghini, and G. Zamboni. in press. "New generation platforms for exploration of crowdsourced geo-data". In Changing the World One Pixel at a Time, edited by Mathieu, P. P., and C. Aubrecht. Springer Berlin Heidelberg.

Camara, G., and F. Fonseca. 2007. "Information policies and Open Source Software in developing countries." Journal of the American Society for Information Science and Technology 58: 121-32. doi:10.1002/asi.v58:1

Cannata, M., and M. Antonovic. 2015a. "Sensor Observations Service for Environmentally Optimizing Irrigation: istSOS within the ENORASIS Example." International Journal of Geoinformatics 11 (3): 1-8. http://journals.sfu.ca/ijg/index.php/journal/article/view/622 (accessed: 28 Feb 2016) 
Cannata, M., and M. Antonovic. 2015b. "SITGAP2, a decision support system for floods management based on open source and open standards." Geomatics Workbooks 12: 459-462.

http://geomatica.como.polimi.it/workbooks/n12/FOSS4Geu15_submission_82.pdf (accessed: 27 Feb 2016)

Cavada, N., Barelli, C., Ciolli, M., and F. Rovero. 2016. "Primates in Human-Modified and Fragmented Landscapes: The Conservation Relevance of Modelling Habitat and Disturbance Factors in Density Estimation." PLoS ONE 11 (2): e0148289. doi:10.1371/journal.pone.0148289

Chen, D., Shams, S., C. Carmona-Moreno, and, A. Leone. 2010. "Assessment of open source GIS software for water resources management in developing countries." Journal of Hydro-environment Research 4 (3): 253-264. doi:10.1016/j.jher.2010.04.017

Chen, J., Chen, J., Liao, A., Cao, X., Chen, L., Chen, X., He, C., Han, G., Peng, S., Lu, M., Zhang, W., Tong, X., and J. Mills. 2014. "Global Land Cover Mapping at 30m Resolution: a POK-based Operational Approach.” ISPRS Journal of Photogrammetry and Remote Sensing 103: 7-27. doi:10.1016/j.isprsjprs.2014.09.002.

Choi, J., Kim, H., Ahn, J., and J. Kim. 2015. "FOSS4G for Rapidly Urbanizing Cities and UN Sustainable Development Goals (SDGs); SDG 11 Cities and Human Settlement”. Presented at FOSS4G 2015, Seoul, September 14-19, 2015. http://www.slideshare.net/junyoungchoi50159/foss4g-for-rapidly-urbanizingcities-and-un-sustainable-development-goalssdgs-sdg-11-cities-and-humansettlement (accessed: 25 Feb 2016)

Craglia, M., Goodchild, M. F., Annoni, A., Camara, G., Gould, M., Kuhn, W., Mark, D., Masser, I., Maguire, D., S. Liang, and E. Parsons. 2008. "Next-Generation Digital Earth: A position paper from the Vespucci Initiative for the Advancement of Geographic Information Science.” International Journal of Spatial Data Infrastructures Research 3: 146-167. doi:10.2902/1725-0463.2008.03.art9

Craglia, M., de Bie, K., Jackson, D., Pesaresi, M., Remetey-Fülöpp, G., Wang, C., Annoni, A., Bian, L., Campbell, F., Ehlers, M., van Genderen, J., Goodchild, M., 
Guo, H., Lewis, A., Simpson, R., Skidmore, A., and P. Woodgate. 2012. "Digital Earth 2020: towards the vision for the next decade." International Journal of Digital Earth 5 (1): 4-21. doi:10.1080/17538947.2011.638500

Getman, Dan. "Visualization and Analysis of Spatiotemporal Data Using Free and Open Source Software at the National Renewable Energy Laboratory." Presented at GIS on the Rockies, Denver, September 24, 2015. http://www.slideshare.net/GISITR/2015-foss4g-track-visualization-andanalysis-of-spatiotemporal-data-using-free-and-open-source-software-at-thenational-renewable-energy-laboratory-by-dan-getman (accessed 28 Feb 2016)

Ellis, J., and J. P. Van Belle. 2009. “Open source software adoption by South African MSEs: barriers and enablers." In Proceedings of the 2009 Annual Conference of the Southern African Computer Lecturers' Association, 41-49. ACM. doi:10.1145/1562741.1562746

Erlich, Z., and R. Aviv. 2007. "Open Source Software: Strengths and weaknesses.” In Handbook of Research Open Source Software: Technological, Economic and Social Perspectives, edited by St. Amant, K., and B. Still,184-96. Hershey, PA, IGI Global. doi:10.4018/978-1-59140-999-1.ch015

Fitzgerald, B. 2011. "Open source software adoption: anatomy of success and failure." International Journal of Open Source Software \& Processes v1 i1, 1-23. doi:10.4018/978-1-60960-513-1.ch001

Frysinger, S. P., R. P. Thomas, and A. M. Parsons. 1993. "Hydrological modelling and GIS: the Sandia environmental decision support system.” In Applications of Geographic Information Systems in Hydrology and Water Resources. Proceedings of the International Conference HydroGIS '93, Vienna, IAHS publication no. 211, 45-50. http://hydrologie.org/redbooks/b211/211006.pdf (accessed 28 Feb 2016)

Future Earth Norway Secretariat. 2015. "Future Earth Norway". http://www.futureearth.org/sites/default/files/files/Summary\%20and \%20Reflections_Future\%20Earth\%20Norway $\% 207 \% 20$ May \%202015\%20Workshop\%20\%281\%29.pdf (accessed 28 Feb 2016) 
Future Earth Secretariat. 2013. "Future Earth Initial Design: Report of the Transition Team". Paris: International Council for Science (ICSU). http://www.icsu.org/future-earth/media-centre/relevant publications/futureearth-initial-design-report (accessed 28 Feb 2016)

Future Earth Secretariat 2014. "Future Earth 2025 Vision". http://www.futureearth.org/sites/default/files/files/Future-Earth_10-yearvision_web.pdf (accessed 28 Feb 2016)

Holmes C, A. Doyle, and M. Wilson. 2005. "Towards a Free and Open Source Spatial Data Infrastructure." In Proceedings of the Faraohs to Geoinformatics FIG Working Week 2005 andGSDI-8, Cairo, April 16-21 2005.

Garegnani, G., Geri, F., Zambelli, P., Grilli, G., Sacchelli, S., Paletto, A., Curetti, G., Ciolli, M., and D. Vettorato. 2015. "A new open source DSS for assessment and planning of renewable energy: r. green.” Geomatics Workbooks 12: 39-49. http://geomatica.como.polimi.it/workbooks/n12/FOSS4Geu15_submission_81.pdf (accessed 28 Feb 2016)

Giera, J., and A. Brown. 2004. "The Costs and Risks of Open Source.” Report, Forrester Research. http://www.joassoc.com/inc/whitepapers/FRSTRossCosts0404.pdf (accessed 28 Feb 2016)

Goodchild, M. F. 2007. "Citizens as sensors: the world of volunteered geography." GeoJournal 69 (4), 211-221. doi:10.1007/s10708-007-9111-y

Goodchild, M. F., Guo, H., Annoni, A., Bian, L., de Bie, K., Campbell, F., Craglia, M., Ehlers, M., et al. 2012. "Next-generation Digital Earth.” In Proceedings of the National Academy of Sciences 109 (28): 11088-11094. doi:10.1073/pnas.1202383109

Gore, A. 1998. "The Digital Earth: Understanding our planet in the 21st Century." Australian surveyor 43 (2), 89-91. doi:10.1080/00050326.1998.10441850

GNU Project 1996. "What is free software? The free software definition." http://www.gnu.org/philosophy/free-sw.en.html (accessed 28 Feb 2016) 
Han, G., Chen, J., He, C., Li, S., Wu, H., Liao, A., and S. Peng. 2015. “A web-based system for supporting global land cover data production." ISPRS Journal of Photogrammetry and Remote Sensing 103: 66-80.

doi:10.1016/j.isprsjprs.2014.07.012

Hauge, Ø., Cruzes, D. S., Conradi, R., K. S. Velle, and T. A. Skarpenes. 2010. "Risks and risk mitigation in open source software adoption: Bridging the gap between literature and practice.” In Open source software: new horizons, 105-118. Springer Berlin Heidelberg. doi:10.1007/978-3-642-13244-5_9

Hippel, E. V., and G. V. Krogh. 2003. "Open source software and the "privatecollective" innovation model: Issues for organization science." Organization science 14 (2), 209-223. doi:10.1287/orsc.14.2.209.14992

James, J. 2003. "Free software and the digital divide: Opportunities and constraints for developing countries". Journal of Information Science 29, 25-33.

Jirka, S., Mihai Toma, D., del Rio, J., and E. Delory. 2014. “A Sensor Web architecture for sharing oceanographic sensor data." In Proceedings of the Sensor Systems for a Changing Ocean (SSCO), Brest, October 13-17 2014, IEEE, 1-4. doi:10.1109/SSCO.2014.7000365

Jirka, S., Hollmann, C., Rieke, M., Blomgren, H., Grothe, M., Berkhout, H., Bush, T., Olav, P., and M. Ross-Jones. 2015. "Using the OGC SOS Interface for Reporting Ambient Air Quality Data." In Adjunct Proceedings of the 29th EnviroInfo and 3rd ICT4S Conference 2015, Copenhagen, September 7-9, 2015. http://enviroinfo.eu/sites/default/files/pdfs/vo19073/0202.pdf (accessed $28 \mathrm{Feb}$ 2016)

Kerkhof, H., and M. Becht. 2006. Natural Hazard research in the Bavarian Alps - A case study of Mittenwald (Germany). SAGA: Analysis and Modelling Applications 115: 75-84.

Kwan, S. K., and J. West. 2005. "A conceptual model for enterprise adoption of open source software." The standards edge: Open season, 1-14. doi:10.1.1.93.8832

Hall, G. B. and M. G. Leahy. 2008. Open source approaches in spatial data handling. Berlin Heidelberg: Springer. doi:10.1007/978-3-540-74831-1 
Hauge, Ø., Cruzes, D. S., Conradi, R., K. S. Velle, and T. A. Skarpenes. 2010. "Risks and risk mitigation in open source software adoption: Bridging the gap between literature and practice." In Open source software: new horizons, edited by Ågerfalk, P., Boldyreff, C., González-Barahona, J. M., Madey, G. R., and J. Noll, 105-118. Springer Berlin Heidelberg. doi:10.1007/978-3-642-13244-5_9

Hofierka, J., and M. Š́ri. 2002. "The solar radiation model for Open source GIS: implementation and applications." In Proceedings of the Open source GISGRASS users conference, 1-19. https://www.researchgate.net/profile/Jaro_Hofierka/publication/2539232_The $\mathrm{s}$ olar radiation model for Open source GIS implementation and applications llinks/5523c2c50cf2c74f0dff0cc0.pdf (accessed 28 Feb 2016)

Ianni, E., Geneletti, D., and M. Ciolli. 2015. "Revitalizing Traditional Ecological Knowledge: A Study in an Alpine Rural Community." Environmental management 56 (1): 144-156. doi:10.1007/s00267-015-0479-Z

Li, Y., Tan, C. H., H. Xu, and H. H. Teo. 2011. "Open source software adoption: motivations of adopters and motivations of non-adopters." ACM SIGMIS Database 42 (2), 76-94. doi:10.1145/1989098.1989103

Macredie, R. D., and K. Mijinyawa. 2011. "A theory-grounded framework of open source software adoption in SMEs." European Journal of Information Systems 20 (2), 237-250. doi:10.1057/ejis.2010.60

Mitasova, H., and M. Neteler. 2004. "GRASS as open source free software GIS: accomplishments and perspectives." Transactions in GIS 8 (2), 145-154. doi:10.1111/j.1467-9671.2004.00172.x.

Meeker, H. J. 2008. The open source alternative: understanding risks and leveraging opportunities. John Wiley \& Sons.

Minghini M. 2014. "Multi-dimensional GeoWeb platforms for citizen science and civic engagement applications." PhD Thesis, Politecnico di Milano, Italy. http://hdl.handle.net/10589/89726 (accessed 28 Feb 2016)

Molina, Martin, and Salvador Bayarri. 2011. "A Multinational SDI-based System to Facilitate Disaster Risk Management in the Andean Community." Computers \& Geosciences: 1501-510. Print. doi:10.1016/j.cageo.2011.01.015 
Moreno-Sanchez, R. 2012. Guest Editorial. "Free and Open Source Software for Geospatial Applications (FOSS4G): A mature alternative in the geotechnologies arena." Transactions in GIS 16 (2): 81-88. doi:10.1111/j.14679671.2012.01314.x

Moreno-Sanchez, R., G. Anderson, J. Cruz and M. Hayden. 2007. "The potential for the use of Open Source Software and Open Specifications in creating web-based cross-border health spatial information systems." International Journal of Geographical Information Science 21 (10): 1135-1163. doi:10.1080/13658810701300113

Morgan, L., and P. Finnegan. 2007. "How perceptions of open source software influence adoption: an exploratory study." https://ulir.ul.ie/bitstream/handle/10344/1980/2007_Morgan.pdf?sequence=2

Nagy, D., A. M. Yassin, and A. Bhattacherjee. 2010. “Organizational adoption of open source software: barriers and remedies." Communications of the ACM 53 (3), 148-151. doi:10.1145/1666420.1666457

Nakayama, Yu, and Suguru Mori. 2012. "FOSS4G Based Mobile Web-GIS for Field Survey in Natural Environmental Studies." 9th International Conference on Ubiquitous Intelligence and Computing and 9th International Conference on Autonomic and Trusted Computing. doi:10.1109/uic-atc.2012.38

Noronha, F. 2002. “Open Source Software opens new windows to third-world.” Linux Journal, May 3, 2002. http://www.linuxjournal.com/article/6049 (accessed 25 Feb 2016)

Noronha, F. 2003 “Developing countries gain from Free/Open Source Software.” Linux Journal, May 20, 2003. http://www.linuxjournal.com/article/6884 (accessed 25 Feb 2016)

Neteler, M., Roiz, D., Rocchini, D., C. Castellani, and A. Rizzoli. 2011. "Terra and Aqua satellites track tiger mosquito invasion: modelling the potential distribution of Aedes albopictus in north-eastern Italy." International journal of health geographics 10 (49). doi:10.1186/1476-072X-10-49 
Open Geospatial Consortium. 2015. OGC® SensorThings API. OpenGIS® Candidate Standard, version 0.9.4. https://portal.opengeospatial.org/files/? $\underline{\text { artifact id }=64146}$ (accessed $25 \mathrm{Feb} 2016)$

Petrasova, A., Harmon, B., Petras, V., and Mitasova, H. 2015. "Tangible Modeling with Open Source GIS”. Springer International Publishing. doi:10.1007/978-3-319$25775-4$

Pitt, J. P., D. J. Kriticos, and M. B. Dodd. 2011. "Temporal limits to simulating the future spread pattern of invasive species: Buddleja davidii in Europe and New Zealand.” Ecological modelling 222 (11): 1880-1887. doi:10.1016/j.ecolmodel.2011.03.023

Qu, W. G., Z. Yang, and Z. Wang. 2011. "Multi-level framework of open source software adoption." Journal of Business Research 64 (9), 997-1003. doi:10.1016/j.jbusres.2010.11.023

Rajani N, J. Rekola, and T. Mielonen. 2003. "Free as in Education Significance of the Free/Libre Open Source Software for Developing Countries.” Helsinki, Finland, Ministry of Foreign Affairs. http://www.itu.int/wsis/docs/background/themes/access/free_as_in_education_ni ranjan.pdf (accessed 28 Feb 2016)

Sanz-Salinas, J. C., and M. Montesinos-Lajara. 2009. "Current panorama of the foss4g ecosystem.” Upgrade 10 (2), 43-51. http://www.cepis.org/upgrade/files/issue \%20II-2009-sanzsalinas.pdf (accessed 28 Feb 2016)

Schenker J L. 2003. “Open Source Software gets boost at UN.” International Herald Tribune, The IHT Online, December 11, 2003. http://cds.cern.ch/record/729867/?ln=en (accessed 25 Feb 2016)

Stewart, K. J., and S. Gosain. 2006. "The impact of ideology on effectiveness in open source software development teams." Mis Quarterly 30 (2), 291-314. http://flosshub.org/sites/flosshub.org/files/stewartgosain2.pdf (accessed $25 \mathrm{Feb}$ 2016)

Steiniger, S., and E. Bocher. 2009. "An overview on current free and open source desktop GIS developments." International Journal of Geographical Information Science 23 (10), 1345-1370. doi:10.1080/13658810802634956. 
Steiniger, S., and A. J. Hunter. 2012. "Free and open source GIS software for building a spatial data infrastructure." Geospatial free and open source software in the 21st century, 247-261. doi:10.1007/978-3-642-10595-1_15

Steiniger, S., and A. J. Hunter. 2013. "The 2012 free and open source GIS software map-A guide to facilitate research, development, and adoption." Computers, Environment and Urban Systems 39: 136-150.

doi:10.1016/j.compenvurbsys.2012.10.003

Š́ri, M., Huld, T., E. D. Dunlop, and J. Hofierka. 2007. "Solar resource modelling for energy applications.” In Digital Terrain Modelling: 259-273. Springer Berlin Heidelberg. doi:10.1007/978-3-540-36731-4_11

Swain, Nathan R., Kilisimasi Latu, Scott D. Christensen, Norman L. Jones, E. James Nelson, Daniel P. Ames, and Gustavious P. Williams 2015. “A Review of Open Source Software Solutions for Developing Water Resources Web Applications.” Environmental Modelling \& Software, 108-17. doi:10.1016/j.envsoft.2015.01.014

Swiss Confederation. 2015. "2015 eGovernment special prize awarded to geo.admin.ch, the geoportal of the Swiss Confederation." https://www.news.admin.ch/message/index.html?lang=en\&msg-id=59628 (accessed 28 Feb 2016)

Tattoni, C., Ciolli, M., and F. Ferretti. 2011. "The fate of priority areas for conservation in protected areas: a fine-scale Markov chain approach.” Environmental Management 47(2): 263-278. doi:10.1007/s00267-010-9601-4

Välimäki, M., V. Oksanen, and J. Laine. 2005. “An empirical look at the problems of open source adoption in Finnish municipalities." In Proceedings of the 7th international conference on electronic commerce, 514-520. ACM. doi:10.1145/1089551.1089643

Ven K, Verelst J, and H. Mannaert . 2008. "Should you adopt Open Source software." IEEE Software 25 (3): 54-59. doi:10.1109/MS.2008.73

Viorres, N., Xenofon, P., Stavrakis, M., Vlachogiannis, E., P. Koutsabasis, and J. Darzentas. 2007. "Major HCI challenges for open source software adoption and development." In Online Communities and Social Computing, edited by D. 
Schuler, 455-464. Springer Berlin Heidelberg. doi:10.1007/978-3-540-732570_50

Wambui, M. 2004. "Africa Should Make More Use of Free and Open Source Software.” Nairobi, Kenya, United Nations Economic Commission for Africa. http://www.uneca.org/eca_resources/news/042805disdcodi_dna.htm (accessed 25 Feb 2016)

Woods, D. and G. Guliani. 2005. Open Source for the Enterprise: Managing risks, reaping rewards. O'Reilly Media.

Yangyong, Z., and X. Yun. 2015. “Defining Big Data.” Big Data Research 1 (1), 2015007. doi:10.11959/j.issn.2096-0271.2015007

Yao, X. and L. Zou. 2008. "Interoperable internet mapping — an open source approach." Cartography and Geographic Information Science 35 (4): 279-293. General OneFile. doi:10.1559/152304008786140560 